\title{
Current MRC Funding and Neuroscience Research Training in Canada
}

\author{
Pierre Bois \\ President, Medical Research Council of Canada
}

Editors Note: The following is the text of a presentation given by Dr. Bois to a meeting of the Canadian Association for Neurosciences in Boston, Massachusetts, November 7, 1983.

Can. J. Neurol. Sci. 1984; 11:82-83

I am very pleased to have an opportunity of addressing the Canadian Association for Neuroscience again at a meeting of the Society for Neuroscience, this time in Boston.

Last year, I reviewed the funding situation of the Medical Research Council of Canada. You will recall that although the apparent increase due to inflation was quite substantial between 1971 and 1981, the real increase in the budget in constant dollars was rather small, amounting to only a few million dollars. The situation has now changed substantially since the approval by the federal government of our five-year plan, with a significant allocation of new funds for 1983-84 and 1984-85. For the first time in many years the budget of MRC has increased significantly over inflation. In current dollars for this year and next year, the increase is of the order of 40 million dollars. This is the first time $\mathrm{I}$ can recollect $\mathrm{MRC}$ being awarded a budget for a period of 2 years and therefore we now know precisely the amount that will be available for 1984-85.

We must express our appreciation to our Minister Madame Monique Bégin for such a marked improvement in the overall situation. This represents a renewed commitment by the Canadian federal government to health research.

The five-year plan identifies a certain number of areas where supplementary support should be allocated such as basic research through the grants program, including the multi-disciplinary approach. Attention was also given to means of improving the situation in institutions and regions with special needs. Another priority is the personal support of scientists including the training of new scientists especially in the clinical field and in biotechnology. Also stressed is the availability of new funding for major equipment. Of course, the plan is not rigid. It provides a general outline of areas of priority and will have to be updated each year. It must be considered merely as an instrument in an on-going process.

I would like now to review the current status of training in the neurosciences. The information on Figures 1,2 and 3 is part of a study undertaken by Mr. Michael O'Brecht of MRC's Planning Division. Four reference years have been selected, 1960-61, 1970-71, 1980-81 and 1982-83 and three main sources of support have been identified, the provincial agencies, the private agencies and the federal agencies. This study has some limitations since it does not include trainees who receive funding through the research grants of their supervisors or from other sources in a university, hospital or an institute. Furthermore, a classification of trainees by the department of training does not necessarily provide an accurate reflection of the number of awards in a particular discipline. Be this as it may, the study should be useful in identifying apparent long-term trends that may serve as pointers to more detailed examinations of particular issues.

Figure 1 is a histogram showing the total number of studentships and fellowships in each of the four reference years. It illustrates the fact that there have been major changes both in numbers of awards and sources of funding over the last 20 years. In the voluntary agency sector, funding of fellowships predominates whereas the provincial agencies appear to favor the studentships.

In the sixties, the number of fellowships underwent a better than fourfold increase from 99 to 560 awards. During the seventies, there was no apparent growth in the number of fellowships, but 1982-83 data indicate the beginnings of a new increase. There were 102 more fellowships in 1982-83 than in 1980-81, largely due to an increase in the number of awards from provincial and federal agencies.

There were no studentships at all in 1960-61, yet by 1970-71 there were 296. The number of studentships has increased during the seventies because of the introduction of studentship programs by voluntary and provincial agencies. By 1980-81, there were nearly as many of them as fellowships, 513 studentships compared to 561 fellowships. The $1982-83$ data indicate a continued growth.

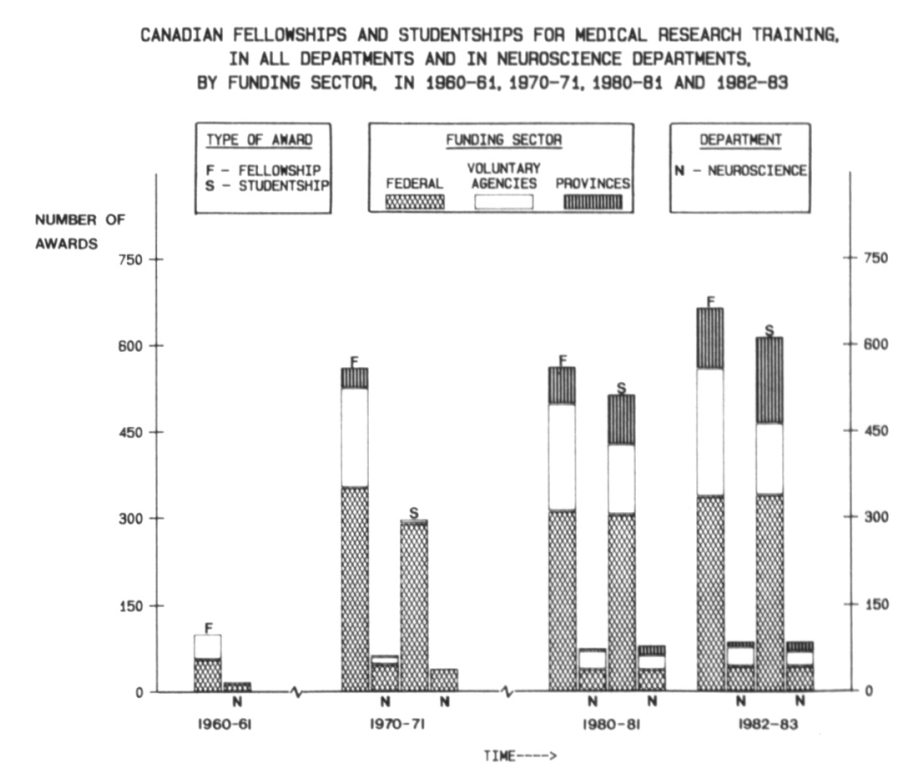

Figure I 
CANADIAN FELLOWSHIPS AND STUDENTSHIPS FOR MEDICAL RESEARCH TRAINING IN NEUROSCIENCE DEPARTMENTS, BY FUNDING SOUACE 1960-61, 1970-71, 1980-81 AND 1982-83

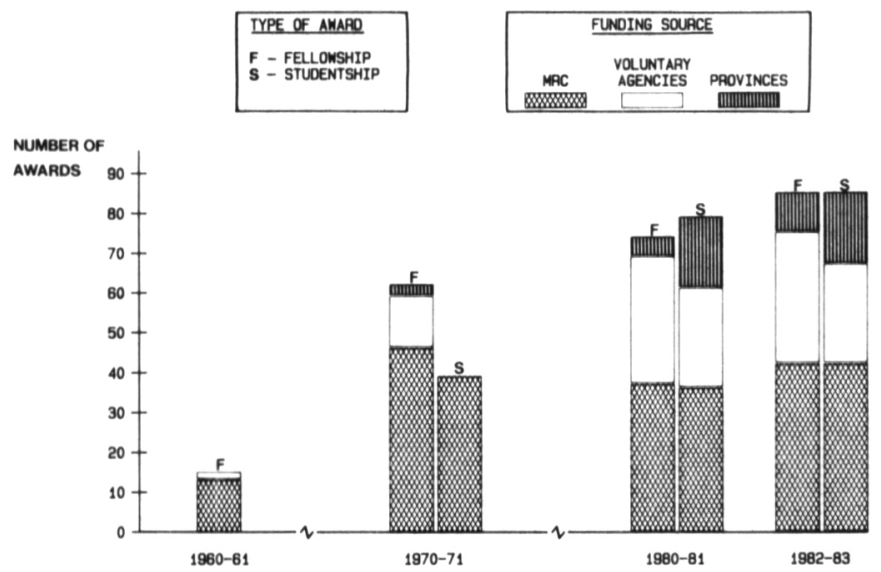

Figure 2

TIME---->

In each of the four reference years, the federal agencies have supported at least half of all students and fellows. The voluntary sector has been the second largest funder of fellowships and in general, provides more fellowships than studentships. For instance, in 1982-83, voluntary agencies provided 97 more fellowships than studentships (222 compared to 125). On the other hand, the provincial agencies generally provide more studentships than fellowships.

The study indicates that the number of trainees in neuroscience departments has grown at about the same rate as the total number of fellows and students in all disciplines (Figure 2). The percentage of awards held in neuroscience departments has been fairly steady at around $13 \%$ and over the long term shows no major upward or downward trend. In the last 2 reference years, the voluntary agencies have given a higher proportion of their total awards to neuroscience departments than the provincial or federal agencies.

In 1980-81, 13.2\% of all fellowships were held in neuroscience departments; in 1982-83, the figure was very similar: $12.8 \%$. It should be noted that the increase in voluntary-agency awards in all disciplines from 1980-81 to 1982-83 was mainly due to additional fellowships offered by the National Cancer Institute, the Arthritis Society and the Heart Foundation. Of these three agencies, only the Heart Foundation has tended to fund awards in neuroscience departments.

In 1980-81, 15.4\% of all student ships were held in neuroscience departments whereas in 1982-83, the percentage was 13.8. The 1.6 decrease in percentage can be attributed to a rapid increase in the total number of studentships funded by provincial agencies which has not been accompanied by a corresponding increase in the number of studentships in neuroscience. However, as mentioned earlier, the small decrease from 1980-81 to 1982-83 in the percentage of awards in neuroscience departments does not seem to reflect any significant long-term trend.

Figure 3 illustrates the distribution of awards in behavioural sciences which I thought might be of interest because of the closeness of this field to the neurosciences.

From 1980-81 to 1981-82, the number of studentships in behavioural science departments increased from 50 to 75 which represents $12.3 \%$ of the total. On the other hand, the number of fellowships increased from 9 to 18 , that is $2.7 \%$ of the total. This
FELLOWSHIPS AND STUDENTSHIPS PROVIDED BY CANADIAN HEALTH SCIENCE GRANTING AGENCIES TO TRAINEES IN BEHAVIORAL SCIENCE DEPARTMENTS BY FUNDING SECTOR, 1970-71, 1980-81 AND 1982-83

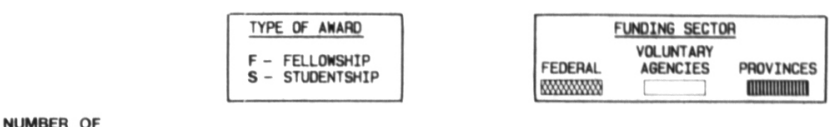

NUMBER OF

AWARDS

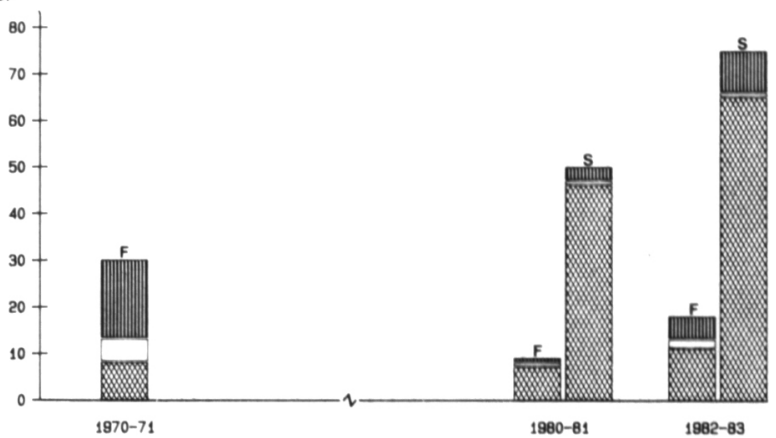

Figure 3

TIME--->

would seem to indicate that very few candidates in the behavioural sciences apply for post-graduate training.

I should mention that, when we look at the overall situation, in all reference years MRC and the Heart Foundation were the top two providers of fellowships. The Arthritis Society, the Muscular Dystrophy Association and the Fonds de la recherche en santé du Québec (FRSQ) have also been steady contributors of fellowships. In 1982-83, a new contributor, the province of Alberta, funded the third largest number of fellowships in Canada.

For studentships, MRC, the Quebec FRSQ and the Heart Foundation were the overall top three providers. The province of Alberta was the fourth largest contributor in 1982-83. To these, one must add the Muscular Dystrophy Association and the National Cancer Institute.

As far as neuroscience departments are concerned, however. MRC, the Heart Foundation and the Muscular Dystrophy Association were among the principal contributors of fellowships; for studentships, the same three agencies together with the Quebec FRSQ are the main sources.

Finally, in the past 20 years, there has been a large growth in the number of Canadian agencies providing awards for research training. Some agencies give preference to post-Ph.D. and post-professional degree awards whereas others tend to fund more graduate student awards. Some agencies have an important impact on the support of training in neuroscience departments whereas others have little or none at all. However. despite the complexity of the system, it seems to have produced a fairly consistent distribution of awards to neuroscience departments.

In closing, I wish to reiterate that the Medical Research Council has always given special attention to the support of research in the neurosciences. At present, about $11 \%$ of the total MRC budget supports research in neuroscience including training of researchers. However, the early beginnings of research in neuroscience in Canada in the thirties were largely due to American support. I am thinking of the days of Wilder Penfield, William Cone and many other well known pioneers. United States funding agencies were very generous, especially the National Institute of Health, the National Science Foundation and the Rockefeller Foundation. I should like therefore to end by thanking them once again for their original assistance which has been largely responsible for the strength and success your discipline and association enjoy today. 